\title{
A produção da desigualdade na escolarização: aspectos da vida contemporânea e o trabalho pedagógico
}

\author{
The production of inequality in elementary school: \\ aspects of conteporary life and the pedagogical work
}

\author{
La producción de la desigualdad en la escolaridad: \\ aspectos de la vida contemporánea y el trabajo pedagógico
}

ALDA JUNQUEIRA MARIN*

\begin{abstract}
RESUMO - Neste artigo são examinados alguns dados de pesquisa pela perspectiva da meta-análise. Focalizase o início do ensino fundamental quer pelo trabalho pedagógico realizado em diferentes âmbitos da escola quer por problemas na formação de professores para atuar nessas séries. Estabelece-se relação com um dos temas contemporâneos mais candentes da vida e educação brasileiras: o domínio da leitura e da escrita. São realçados aspectos das ações desses âmbitos que colaboram com a produção/reprodução de desigualdades sociais, este um tema social histórico. Aponta-se, ao final, a relevância da crítica e a necessidade da divulgação para os formadores de professores e formandos em cursos iniciais ou de educação continuada.
\end{abstract}

Palavras-chave - Séries iniciais do ensino fundamental. Formação de professores. Escolarização. Produção de desigualdades. Leitura e escrita.

\begin{abstract}
This article put questions about some data from researches by means of a meta-analyzes. The focus is the elementary school in its first series so much by means of the pedagogical work realized into many classrooms as much by means of problems of teacher's education which will work at these schools. Are reached relations with one of the most important contemporary themes of Brazilian social life and education: to dominate the reading matter and writing. Some aspects are emphasized about these fields of action which cooperate with production/reproduction of historical social inequalities. At end are pointed the importance of the critics and the need to become known these data to teachers that are educating new future teachers, students in courses to be new teachers or those teachers which are working and receive continuing education.
\end{abstract}

Keywords - First school year in elementary school. Teacher's education. Production of inequalities. Reading matter and writing.

RESUMEN - Este artículo examina algunos dados de investigación por la perspectiva de la meta-análisis. El foco está en los primeros años de la escuela primaria tanto por el trabajo pedagógico realizado en diversos lugares de la escuela cuánto por problemas de la formación de los estudiantes que cursaban la enseñanza superior para seren maestros de los años de la escuela primaria. Busca establecer relaciones con uno de los más importantes temas contemporáneos de la vida social e educativa del Brasil: el dominio de la lectura e de la escritura. Algunos aspectos son realzados sobre eses sectores de acción que cooperan con la producción e reproducción de las desigualdads sociales históricas. En conclusión es necesario señalar la importancia de las críticas e la necesidad de la divulgación para los que forman maestros, para los que estudian para ser maestros e también los maestros que están en educación continuada.

Palabras clave - Primero año escolar de la enseñanza primaria. Formación de maestros. Producción de desigualdades. Lectura y escrita.

\footnotetext{
* Doutora em Educação pela Faculdade de Filosofia Ciências e Letras de Rio Claro (Rio Claro, SP, Brasil) e Professora da Pontifícia Universidade Católica de São Paulo (São Paulo, SP, Brasil). E-mail:<aldamarin@pucsp.br>.
} 


\section{INTRODUÇÃO}

As pesquisas e estudos realizados nos últimos anos têm sido oportunidades relevantes para o acesso à educação escolar. Por meio de dados obtidos em algumas pesquisas divulgadas, é possível detectar diversos aspectos da vida contemporânea e sua relação com a escola. Dentre esses temas contemporâneos, podem ser exemplificados os estudos sobre interculturalidade (LEITE, 2009); multiculturalismo (CARRANO, 2008); incremento crescente da tecnologia (PEIXOTO, 2011; TOSCHI, 2011); as desigualdades e diversidades (FREITAS, 2006; MARIN, 2006; BUENO, 2006; SOARES, 2006); as diferenças étnico-raciais e de gênero (CARVALHO, 2008; LOPES, 2008; GOMES, 2008; BLACKMORE, 2013); sobre a globalização, as políticas econômicas, sociais e educacionais (GOMES, 2008; MARTINS, 2011; CAIADO; CAMPOS; VILARONGA, 2011).

Dentre tais estudos, e certamente muitos outros, cresce a relevância de análises a respeito das bases sobre as quais todas essas investigações ocorrem, quais sejam, o ensino e o aprendizado das noções básicas de alfabetização para o acesso aos conhecimentos, sobretudo os conhecimentos escolares, quaisquer que sejam eles, além das tentativas de reformas constantes e suas possibilidades e limites para a formação humana. Trata-se, portanto, e sobretudo, de professores e de alunos em suas funções dentro de escolas.

No projeto coletivo de pesquisa que desenvolvemos, estão em foco as práticas e os meios pelos quais consideramos poder flagrar o que realmente a escola realiza na educação. É por meio dessa perspectiva que são descritos e analisados os agentes da escola, não de modo abstrato, mas, sim, de detectar que ações ou práticas (GIMENO, 1998) são exercidas na situação escolar envolvendo-os em nome da educação. Em boa parte dessas pesquisas estão temas variados, mas que perpassam pelas questões dos conhecimentos escolares básicos apontados. Neste texto estão alguns resultados de pesquisas abrangendo tais temas envolvendo alunos e professores com toda a concretude possível.

\section{Desigualdades}

Entre tantos eixos analíticos possíveis na vida contemporânea e sua presença nas escolas, toma-se aqui o das desigualdades, por considerar que boa parte das demais características da contemporaneidade está presente na escola juntamente com as desigualdades reproduzidas por ela. Assim, alguns excertos apresentados a seguir permitem a visão das questões segundo a abordagem social de Bourdieu (1998, 2001a, b, c), que deve ser considerada também como pedagógica pelo que ele nos ensina ao analisar a escola.
Nem sempre as pesquisas aqui focalizadas, na sua origem, usaram esse referencial, pois são variadas as fontes teóricas, mas sempre críticas. No entanto, neste texto há meta-análise, reanalisando conjunto de dados, os quais são, por vezes, considerados esparsos, mas que perdem essa característica diante de dois argumentos teóricos. Um deles vem do próprio Bourdieu (1998) ao nos ensinar a pensar "relacionalmente um caso particular constituído em caso particular do possível, tomandose como base as homologias estruturais" e detectar "caracteres invariantes [dos casos] que podem se ocultar debaixo das aparências da singularidades" (p. 33). Além disso, há que se pensar sobre a possibilidade de situações agrupadas por serem originadas em escolas públicas, portanto com situações muito similares, a se considerar a contribuição de Vincent, Lahire e Thin (2001) sobre a história e a teoria da forma escolar, forma hegemônica que se disseminou na era moderna.

A primeira ideia-força apresentada por Bourdieu (2001a), surgida em seu texto original em 1966, aqui referido em sua tradução na $3^{\mathrm{a}}$ edição e orientadora deste texto para a meta-análise, é a de que a escola constitui "um dos fatores mais eficazes de conservação social, pois fornece a aparência de legitimidade às desigualdades sociais e sanciona a herança cultural e o dom social tratado como dom natural" (p. 41). Essa ideia central ganha força ainda maior quando aponta que o rigor da escola pesa de modo diferenciado sobre os sujeitos de diferentes origens e, ainda, que não basta apontar essa desigualdade, mas que é "necessário descrever os mecanismos objetivos que determinam a eliminação contínua das crianças desfavorecidas" (p. 41), para excluí-las de seu ambiente ou excluí-las internamente nesse mesmo ambiente (BOURDIEU, 2001b), qual seja, o que pretende fornecer domínio do conhecimento e as formas de usá-lo em benefício do ser humano.

\section{Alunos E PROFESSORES}

Tendo alunos e professores como sujeitos em ambientes escolares, aspectos variados de situações de ensino são destacados nos estudos apresentados a seguir sobre as séries iniciais do ensino fundamental.

Ao analisar o trabalho de professores de $1^{\circ}$ ano, Simão (2011) apresenta os aspectos relativos ao desempenho de alunos de uma escola municipal da cidade de São Paulo, Brasil. Por mais que possam ser considerados inadequados os procedimentos de análise avaliativa externa que grassam pelo país, é inegável que eles, de alguma forma, dão visibilidade ao que se faz no interior das escolas às quais não podemos constantemente adentrar, mas podemos ter a informação. Assim, é com certa reserva que podemos ver algumas dessas informações constantes no Quadro 1. 
Quadro 1. Níveis de proficiência em Língua Portuguesa

\begin{tabular}{|l|c|c|c|c|c|c|}
\hline \multirow{2}{*}{ Ano Escolar } & \multicolumn{4}{|c|}{ Prova São Paulo 2009 } & \multirow{2}{*}{ Escola pesquisada } & $\begin{array}{c}\text { Classificação da } \\
\text { Escola pesquisada }\end{array}$ \\
\cline { 2 - 7 } & $\begin{array}{c}\text { Abaixo do } \\
\text { básico }\end{array}$ & Básico & Adequado & Avançado & Adequado \\
\hline $2^{\circ}$ ano ciclo I & $<115$ & de $115 \mathrm{a}<150$ & De $150 \mathrm{a}<200$ & $\geq 200$ & 151,5 & Básico \\
\hline $3^{\circ}$ ano ciclo I & $<135$ & de $135 \mathrm{a}<175$ & de $175 \mathrm{a}<225$ & $\geq 225$ & 172,4 & Básico \\
\hline $4^{\circ}$ ano ciclo I & $<150$ & de $150 \mathrm{a}<200$ & de $200 \mathrm{a}<250$ & $\geq 250$ & 184,2 & \\
\hline
\end{tabular}

Fonte: Portal da Secretaria Municipal de Educação da cidade de São Paulo (SIMÃO, 2011, p. 61).

Não é necessária análise minuciosa para verificar que os indicadores de exigência são mais brandos para o segundo ano, crescendo para os demais. Também se verifica que, a despeito disso, o resultado é sempre muito precário; que a relação entre exigência mínima, apontada na coluna "Básico", e os resultados de todas as séries da escola pesquisada não são superados significativamente quando se avança na escolaridade. É possível apontar que havia um enorme caminho que deveria ter sido percorrido pelos alunos para poder chegar ao nível considerado ideal, o avançado. Tomando-se apenas os resultados do $2^{\circ}$ ano, é possível ter uma ideia do trabalho da escola após dois anos de presença das crianças nas salas de aula, pois as provas são feitas nos períodos de final de ano. Considere-se que, para atingir o nível adequado, as crianças precisam demonstrar a condição de escrever textos alfabeticamente a partir de conhecimentos memorizados sobre diversos gêneros; escrever textos de diversos gêneros de autoria própria, individualmente ou em duplas; reescrever textos (lendas, contos) de próprio punho ou ditando-os ao professor, sendo capazes de recuperar as ideias principais, segundo os critérios estabelecidos pela Secretaria Municipal de Educação da cidade de São Paulo (SIMÃO, 2011, p. 102103). Esta fluência deveria estar presente ao final do $1^{\circ}$ ano da escolarização, mas não está ao final do $2^{\circ}$ ano.

Detectados esses dados, durante muitas horas ao longo de um ano, $2^{\circ}$ semestre de 2010 e $1^{\circ}$ semestre de 2011, Simão (2011) observou turmas de $1^{\circ}$ ano da escola cujos dados foram apresentados no Quadro 1. As crianças desse Quadro foram outras e, justamente por ser o segundo e terceiro anos de implantação da escola de nove anos, a busca era flagrar e compreender possíveis modificações em relação aos anos anteriores, posto que seriam necessárias ainda maiores alterações no trabalho de ensinar nesse início de ciclo fundamental, considerando que nessa época estavam iniciando a escolarização as crianças com seis anos, e não mais com sete.

Verificou-se que essa medida, a da escola de nove anos, não implicou grandes mudanças na organização da escola para receber tais crianças, nem mesmo nas condições materiais (carteiras em tamanho menor, por exemplo), assim como não se verificou alteração no padrão de trabalho pedagógico com as crianças em sala de aula. As características das atividades didáticas seguiram um padrão que já vinha sendo analisado por estudos sobre o primeiro ano em épocas e lugares diferentes (FOINA, 1989; MONTEIRO, 2002; OLIVEIRA, 2001). Os resultados desses estudos apontaram forte ênfase na contenção dos corpos, disciplinarização às regras das escolas e homogeneização do trabalho de alfabetização. Neste, o ensino é dirigido para todas as turmas, seguindo, em cada uma delas, o mesmo ritmo para todas as crianças, as mesmas ordens, as mesmas tarefas, as mesmas noções, independentemente do fato de serem crianças de origem social e de escolaridade anterior diversificada, aliás não investigada pelas professoras.

Assim, no ensino desenvolvido nas duas turmas analisadas por Simão (2011), verificou-se o mesmo padrão: hora para beber água e para ir ao banheiro; não levantar das carteiras sem autorização tanto nas salas de aula quanto na Sala de Leitura ou na de Informática; apreensão das rotinas escolares, tais como o que fazer quando adentra o prédio, atender à campainha para fazer filas, hora de ir para sala de aula, ir para o lanche, voltar para a sala de aula; nas terças-feiras, ir à Sala de Leitura, nas quintas ir à Sala de Informática; o que fazer na hora da saída; atender, nas diferenciadas horas, as ordens de silêncio.

As atividades didáticas também seguiam rotinas: copiar o cabeçalho da lousa; ouvir história lida pela professora, em silêncio, sem poder perguntar; ausência de correções pela professora quando comentava os erros na cópia, deixando as crianças sem compreensão sobre seus erros, apesar de olharem para a lousa e depois para o caderno. $\mathrm{O}$ uso de palavras mal pronunciadas era constante: "losa", "copiô", "acabô", entre outras (p. 92), não auxiliando as crianças a terem uma pronúncia correta, como se exige, depois, nas redações.

A leitura é um dos pontos que merecem destaque, pois as crianças, embora ainda não soubessem ler, deveriam ser estimuladas, principalmente à sua exposição mediante leitura das professoras e à estimulação à interpretação visando à familiaridade de leitura compreensiva. Entretanto, em diversas oportunidades verificou-se a presença de leitura mecânica, o uso dessa atividade 
mantendo as crianças caladas e sentadas levando à dispersão da atenção. Quando houve alguma tentativa de interpretação, esta sempre foi muito rápida e empobrecida. Em uma atividade articulando escrita e leitura, após a cópia de um poema que estava na lousa, a professora leu pedindo que as crianças apenas ouvissem. Depois da leitura, pediu que fizessem leitura coletiva em voz alta. Na sequência, fez algumas perguntas sobre os desejos dos personagens do poema. Em seguida colocou uma questão na lousa e pediu que as crianças escrevessem os nomes dos personagens enumerando-os de 1 a 6 em linhas subsequentes, ou seja, dando pistas de que seriam seis os personagens. As crianças copiaram mecanicamente, não sabiam escrever sozinhas, e algumas nem isso conseguiram fazer. Nesse final de atividade, a professora passou pelas carteiras e mostrava, no texto copiado, o que deveria ser respondido: apontava os nomes dos personagens. Em qualquer análise desse documento, que é o caderno do alunado, essa seria uma atividade bem-sucedida, amostra de ações de como as crianças estariam caminhando bem na direção do domínio da leitura e da escrita; no entanto, levando a interpretações equivocadas, mascarando uma realidade.

Evidentemente, com ações como essas, mesmo depois de 2.000 horas de aula - cinco horas diárias, durante dois anos com 200 dias letivos cada um - não é possível, mesmo, ter resultados tão melhores do que os que foram apontados anteriormente.

É possível flagrar, nesses poucos episódios exemplificadores, a ação da escola pressupondo que as crianças tivessem domínio de tantas condições, tais como ter a de transplantar a percepção da lousa para o caderno - que são planos diferentes de representação do espaço - ou, então, de aquietar-se em todas as situações, em uma fase em que o cognitivo precisa estar acompanhado do afetivo (atenção da professora à criança) e do motor (complementar sua formação física para as exigências da escolaridade), segundo Wallon (1979) e as próprias diretrizes para essa etapa de atendimento educacional. Tais situações analisadas são propiciadoras da manutenção da distância dessas crianças em relação ao fundamental capital cultural a ser fornecido pelas escolas, necessário para a vida nas sociedades contemporâneas. As crianças oriundas dos meios desprivilegiados, econômica, social e culturalmente falando, precisam de cuidados redobrados para a consecução do capital cultural incorporado. O domínio da escrita é uma das principais características para a existência do capital cultural objetivado, ou seja, o modo de demonstrar suas capacidades básicas, um ter que passe a ser, constituindo disposições fundamentais de seu habitus, para que parte da diferença de sua atuação escolar e social seja diminuída em relação a outros grupos sociais que os possuem desde a origem familiar em que tais códigos estão presentes desde o nascimento. Tais características e condições não estiveram presentes nos testes cujo resultado está demonstrado no Quadro 1 nem foram propiciadas para as crianças observadas nos episódios exemplificados.

Em outro trabalho denso investigando a atuação da escola em que a leitura era o foco, Bezerra (2009) também traz elementos sobre a realidade das escolas auxiliando na compreensão da precariedade da formação do alunado em séries mais avançadas do ensino fundamental nessa área fulcral para o restante da vida, que é o letramento. Alguns episódios foram aqui selecionados do conjunto. Partindo da preocupação com o uso da literatura infantil para o ensino dos componentes escolares na escola em que atuava, passou a analisar ações docentes em quatro lugares da escola: a Sala de Leitura, o Laboratório de Ciências, o Laboratório de Informática e salas de aula regulares, ampliando seu foco para a formação do leitor, examinando-a no interior da escola.

Iniciando pela análise da presença da leitura no lugar especificamente destinado a ela - Sala de Leitura -, o estudo inventaria o acervo e outros aspectos das condições materiais de trabalho, analisa a interferência das ações políticas ao longo dos anos desde a década de 1980 e aponta várias facetas desse trabalho com as crianças. $\mathrm{O}$ horário era muito reduzido, ou seja, apenas uma hora por semana, e um acervo pouco usufruído pelas professoras para trabalho diário nas salas de aula, pois de 129 empréstimos no ano, apenas 34 foram para professoras das séries iniciais do ensino fundamental. Entre os vários episódios relatados, alguns exemplos permitem detectar as características dessa formação: o reduzido número de livros nas mãos das crianças, seja para uso na escola, seja para levar para casa; nas leituras de poemas - um dos projetos desenvolvidos -, a preocupação com regras gramaticais foi muito intensa, assim como a transmissão de regras para a escrita; tempo para leitura livre dos alunos muito reduzido, pois sempre há escolhas do que ler feitas pela professora da Sala de Leitura em função do trabalho das salas de aula com os diferentes componentes curriculares; muita leitura em voz alta feita pela professora da Sala de Leitura em detrimento da leitura das próprias crianças, que sempre pedem para que mostre as figuras; troca intensa de livros pelas crianças com superficialidade de aproveitamento da leitura propriamente dita, pois as imagens coloridas atraem, as crianças lidam com o livro como brinquedo (o que, em si, não é um problema) e só depois de um tempo com ele em mãos vão ler algo; as atividades organizadas pela professora têm caráter utilitarista, sempre mais voltado à ideia de que a leitura deva gerar alguma outra atividade seja escrita, dobradura ou desenho. Conforme esperado, nessa fase de final de ano, ao passar para o segundo ano, o predomínio das leituras deveria ser o de texto, ficando em segundo plano a quantidade de imagens. 
A seguir, o texto de Bezerra (2009) aborda o ensino na Sala de Informática, trazendo a informação de que há tentativa de articular com o trabalho da Sala de Leitura e das salas de aula. O foco continua no fazer, pois o texto, o desenho, as histórias em quadrinhos e os poemas são relacionados, alterando-se apenas o suporte para sua execução, pois o que seria feito com lápis e caderno na Sala de Leitura ou nas salas de aula, na Sala de Informática se fazia com o uso da máquina. $\mathrm{O}$ manuseio do equipamento eletrônico está centrado na escrita com uso do processador de texto e desenho da HQ, em detrimento das possibilidades de leitura.

No Laboratório de Ciências, o livro de literatura infantil ou outro tipo de texto é utilizado para dar início ao desenvolvimento de algum conteúdo específico da área, desencadeando sequência de atividades diversificadas próprias do tema em estudo. Ao final das atividades, a professora fazia um mapa conceitual na lousa com auxílio das informações fornecidas pelas crianças, que posteriormente as copiavam no caderno. Havia, da parte da professora de Ciências, a ênfase na leitura pelas próprias crianças, inclusive desenvolvendo com elas uma ficha de leitura, num claro contraponto à atuação das demais professoras vistas até aqui.

As professoras das salas de aula manifestaram a perspectiva de uso da leitura que foi organizada em dois focos centrais: o ensino da leitura em si mesma como parte da formação dos alunos no que tange à literatura e como meio instrumental em diferentes circunstâncias.

A análise das manifestações e situações em salas de aula permitiu verificar a existência de certo padrão no uso da literatura destinada ao público infantil, incluindo certos gêneros presentes nos livros didáticos, tais como as parlendas. As escolhas seguiam certo esquema priorizando fábulas e contos de fada acompanhados pelos contos clássicos da literatura infantil por serem mais simples e exercerem atração junto às crianças até o segundo ano. Foi notório o critério de escolha também pelas questões da veiculação da moralidade, muito presente nos depoimentos que enfatizavam serem oportunidades para o ensino de valores presentes nesses materiais. Para os demais anos, os clássicos ainda tiveram interesse, mas diversificaram-se as escolhas, passando pelas lendas, textos que possuíssem relação com componentes curriculares, literatura infantil de escritores brasileiros, poesias.

Tais escolhas, entretanto, tinham pouco resultado no que tange à formação de leitor, pois os livros, em geral, eram escolhidos e lidos pelas professoras aos alunos, e as atitudes de leitor e habilidades da leitura, em si mesmas, ficavam em segundo plano, muito prejudicadas. Tais atitudes das professoras eram motivadas pela necessidade de articular com componentes curriculares a serem ensinados, com as datas comemorativas, sendo muito utilizadas para a escrita coletiva - realizada na lousa com a participação das crianças -, conforme já se verificou, também, no estudo anteriormente apresentado neste texto, configurando, ao que tudo indica, a disseminação de alternativa didática empobrecedora da escrita das crianças que apenas as copiam da lousa, posteriormente, para efeito de registro no caderno. Mais uma vez evidencia-se que, para qualquer consultor do caderno do alunado, há condição de boa escrita, porém não do aluno (mas apenas cópia), ocasionando o que os testes de avaliação externa comprovam. Caracteriza-se, assim, o uso instrumental da leitura, e não a leitura como parte relevante da formação das crianças como leitoras, evitando a oportunidade para que adquiram essas disposições para seus habitus, necessárias no mundo atual e valorizadas socialmente.

Diante de tais dados exemplificados, há que tecer algumas considerações sobre a formação das professoras envolvidas nesses dois trabalhos e as condições para exercerem suas funções. As ações das professoras do $1^{\circ}$ ano são bastante prejudiciais ao desenvolvimento e ao aprendizado das crianças de seis anos ao transplantar as mesmas atividades e sequências das experiências anteriores com crianças de sete anos, ou seja, a formação das professoras precisaria ter sido complementada com outros aspectos para iniciar a escolarização dessas crianças. Isso não significa dizer que o que elas faziam também estivesse adequado para crianças de sete anos. São oriundas de grupos sociais com baixa escolaridade, mas conseguiram elevar seus patamares de formação, chegando ao ensino superior privado, noturno. Ambas fizeram o curso de Pedagogia, mas, se pudessem, fariam curso de Nutrição e Biblioteconomia, fato que denota certa insatisfação com a atual função. Nas condições de trabalho vivenciadas, havia muitas possibilidades de um trabalho diferenciado: trabalhavam em apenas um turno; havia, na escola, a Sala de Leitura e Laboratório de Informática; enorme acervo de obras; pátios para atividades físicas; crianças que queriam se movimentar e eram curiosas, aspectos favoráveis, a despeito das condições sociais, econômicas e culturais, com familiares ocupados com atividades pouco exigentes do ponto de vista da escolaridade. Porém, ao mesmo tempo, muitos limites, advindos das mesmas condições de trabalho, como a decisão da escola ao atribuir essas turmas a quem já possuía experiência em alfabetização, atrelando esse resultado (de alfabetizar as crianças) à total finalidade desse ano escolar em que aspectos necessários, como a ludicidade, a brincadeira e a socialização, não tiveram lugar.

Quanto às professoras dos outros anos, no segundo estudo, pode-se verificar que eram várias as possibilidades nas condições de trabalho: acervos enormes da Sala de Leitura; existência, também, do Laboratório de Informática com professora à disposição; presença de coordenação 
pedagógica; Laboratório de Ciências; crianças que já tinham algumas condições de leitura e manifestação de preferências e curiosidades. Entretanto, percebem-se vários limites, a começar pela baixa utilização do acervo da escola no que se refere a materiais destinados à própria formação das professoras. Havia enorme acervo, mas as professoras sequer o conheciam na sua íntegra e, portanto, com poucas condições para seleção. Não havia atenção sobre o que estavam efetivamente ensinando às crianças: se a escrita a partir da tela do computador estaria sedimentando algo, se as ações realizadas na sala de aula tinham conexão com o que estaria sendo feito na Informática, se estariam usando com nexo as palavras aprendidas para formular o pensamento e a escrita; a contradição entre o que manifestavam e o que faziam, revelando baixa condição crítica sobre o próprio trabalho; não chegavam a ter noção clara das possibilidades da leitura em geral e da literatura em especial como outra linguagem na área artística; efetivamente, pouca clareza dos objetivos da inserção da leitura dentre os componentes curriculares; confusões entre gêneros literários e as fronteiras entre um gênero e outro.

De modo geral, as professoras de todos os anos estabeleciam relações mecânicas entre leitura e escrita, não diferenciando os dois códigos e suas exigências específicas que podem se beneficiar mutuamente, mas não como elas estavam operando com eles e com as crianças que se iniciavam nesse universo.

Em estudo realizado em outra esfera - a da formação de professoras para atuar nesses anos - foi possível obter dados que permitem completar um pouco esse cenário. A pesquisa (MARIN; GIOVANNI, 2007) realizada com concluintes de curso superior de formação de professoras revelou a precariedade das condições de domínio de conteúdos relativos à leitura e escrita, consideradas, lá como aqui, saberes centrais para a vida da escola. A partir de resultados do uso de três instrumentos que exigiam respostas das alunas em relação a questões que deveriam ser lidas e imagens a serem observadas, foi possível identificar as condições apresentadas por elas para eventual sucesso no desempenho de sua função educativa. Alguns excertos apenas exemplificam situações que apresentam muita similaridade na precariedade de formação vista com os estudos anteriores. A expressão escrita apresentou situações de erro, tais como: "explição" em lugar de "explicação", "estam" em lugar de "estão", "trez" em lugar de "três" (p. 23); problemas de pontuação e de concordância em situações corriqueiras de escrita (p. 24). Em relação a situações muito comuns entre as atividades realizadas nas escolas, quais sejam estabelecer relação entre imagem e um texto escrito: poucos acertos e piores justificativas para as escolhas entre as duas partes da questão, pois, em geral, houve tendência a reproduzir o que o próprio texto apresentava com percepção fragmentada em detrimento da visão de conjunto do que se oferecia. Sobre o domínio de conhecimentos em relação à escrita, verificou-se, em uma questão que pedia análise sobre texto de criança, entre outros dados, a "utilização errônea do conceito de função social da escrita [...]; ausência de identificação de erros ortográficos no texto da criança; incompreensão manifesta da relação entre pensamento e escrita [...]" (p. 35). Percebe-se, assim, que as condições de formação começam bem antes do exercício da função e que a ideia, tão difundida, de que se aprende na profissão contém vários equívocos, sendo esses, alguns deles.

\section{Algumas CONSIDERAÇões}

Verificou-se, sim, de um lado, a positividade da extensão da escolaridade por mais anos de estudo para as crianças e a possibilidade de as professoras expandirem sua escolaridade para além da de seus pais, o que é, sem dúvida, um ganho. Mas, de outro lado das mesmas medidas, identifica-se: a continuidade da presença dos controles, a normatização, o estrito e feroz uso do tempo; a necessidade de manter as crianças ocupadas; a presença de uma sociedade que é a da imagem e da tecnologia, não importa como se usa, pois ajuda pouco tanto para a leitura quanto para a escrita; uma leitura descontextualizada e utilitarista; a presença de uma pedagogia da leitura oralizada pelo professor; uma escrita que não tem autoria, porque é de todos e de ninguém ao mesmo tempo, em que aquilo que fica no caderno é a cópia; a violência simbólica de manutenção da meritocracia, pois as crianças "que se virem" para aprender; a manutenção, ainda, da ordem preexistente, pois o ofertado é o mínimo, tal como explicitado no Quadro 1.

As professoras, que passaram, certamente, por situações como as de seus alunos, reproduzem as mesmas condições: (a) ausência de capital cultural objetivado e incorporado, o que oportunizaria exprimir por escrito sensações, pensamentos, necessidades...; (b) reprodução das desigualdades originárias, transformando o pouco que fornecem em mecanismos classificatórios; (c) fragilidade da aprendizagem - chocante, pois, embora aparente uma conquista, pois algumas crianças conseguirão avançar, mas muitas não, como uma das professoras disse sobre a leitura coletiva: "nem todos acompanham". Estes serão os "excluídos do interior da escola" (BOURDIEU, 2001c): ficam presentes, mas sem acesso ao que lhes é de direito, pelo menos o conhecimento escolar básico.

Alguns mecanismos internos estiveram em funcionamento nos exemplos citados, ainda que sinteticamente. A crítica, necessária, precisa chegar às mãos e aos olhos de outros pesquisadores e, sobretudo, de professores em exercício ou em formação para que possam refletir sobre suas atitudes investigativas e de ensino e façam opções por 
outras condutas didáticas diante das turmas de alunos. Essa é uma das ajudas que a perspectiva sociológica fornece a outros pesquisadores e formadores de professores.

\section{REFERÊNCIAS}

BEZERRA, Maria Helena Bertolini. Formação do leitor: a escola cumpre a função? Tese (Doutorado em Educação: História, Política, Sociedade) - Pontifícia Universidade Católica de São Paulo, 2009.

BLACKMORE, Jill. Organizações educacionais e gênero em tempos de incerteza. In: APPLE, Michael W.; BALL, Stephen J.; GANDIN, Luís Armando (Org.). Sociologia da educação: análise internacional. São Paulo: Penso, 2013. p. 334-346.

BOURDIEU, Pierre. O poder simbólico. Rio de Janeiro: Bertrand Brasil, 1998.

A escola conservadora: as desigualdades frente à escola e à cultura. In: NOGUEIRA, Maria Alice; CATANI, Afrânio Mendes (Org.). Pierre Bourdieu: escritos de educação. Petrópolis: Vozes, 2001a. p. 39-64.

Os três estados do capital cultural. In: NOGUEIRA, Maria Alice; CATANI, Afrânio Mendes (Org.). Pierre Bourdieu: escritos de educação. Petrópolis: Vozes, 2001b. p. 71-79.

Os excluídos do interior. In: NOGUEIRA, Maria Alice; CATANI, Afrânio Mendes (Org.). Pierre Bourdieu: escritos de educação. Petrópolis: Vozes, 2001c. p. 217-227.

BUENO, José Geraldo Silveira. Alunos e alunos especiais como objetos de investigação: das condições sociais às condições adversas. In: FREITAS, Marcos Cezar (Org.). Desigualdade social e diversidade cultural na infância e na juventude. São Paulo: Cortez, 2006. p. 333-359.

CAIADO, Katia Regina Moreno; CAMPOS, Juliane Aparecida de Paula Perez; VILARONGA, Carla Ariela Rios. Estudo exploratório sobre o perfil, a formação e as condições de trabalho do professor. In: CAIADO, Katia Regina Moreno; JESUS, Denise Meyrelles de; BAPTISTA, Claudio Roberto (Org.). Professores e educação especial. Porto Alegre: Mediação, 2011. p. 159-171.

CARRANO, Paulo. Identidades culturais juvenis e escolas: arenas de conflitos e possibilidades. In: MOREIRA, Antonio Flavio; CANDAU, Vera Maria (Org.). Multiculturalismo: diferenças culturais e práticas pedagógicas. Petrópolis: Vozes, 2008. p. 182-211.

CARVAlHO, Marília Pinto de. Gênero na sala de aula: a questão do desempenho escolar. In: MOREIRA, Antonio Flavio; CANDAU, Vera Maria (Org.). Multiculturalismo: diferenças culturais e práticas pedagógicas. Petrópolis: Vozes, 2008. p. 90-124.

FOINA, Luciana Gomide. O primeiro ano na escola. Tese (Doutorado em Educação) - Pontifícia Universidade Católica de São Paulo, 1989.

FREITAS, Marcos Cezar (Org.). Desigualdade social e diversidade cultural na infância e na juventude. São Paulo: Cortez, 2006.

GIMENO, Jose. Poderes inestables en educación. Madrid: Morata, 1998.

GOMES, Nilma Lima. A questão racial na escola: desafios colocados pela implementação da Lei 10.639/03. In: MOREIRA, Antonio Flavio; CANDAU, Vera Maria (Org.).
Multiculturalismo: diferenças culturais e práticas pedagógicas. Petrópolis: Vozes, 2008. p. 67-89.

LEITE, Miriam Soares. Entre a bola e o MP3: novas tecnologias e diálogo intercultural no cotidiano escolar adolescente. In: CANDAU, Vera (Org.). Didática: questões contemporâneas. Rio de Janeiro: Forma e Ação, 2009. p. 121-138.

LOPES, Luiz Paulo Moita. Sexualidade em sala de aula: discurso, desejo e teoria queer. In: MOREIRA, Antonio Flavio; CANDAU, Vera Maria (Org.). Multiculturalismo: diferenças culturais e práticas pedagógicas. Petrópolis: Vozes, 2008. p. $125-148$.

MARIN, Alda Junqueira. Manifestações de professores sobre alunos. In: FREITAS, Marcos Cezar (Org.). Desigualdade social e diversidade cultural na infância e na juventude. São Paulo: Cortez, 2006. p. 285-300.

MARIN, Alda Junqueira; GIOVANNI, Luciana Maria. Expressão escrita de concluintes de curso universitário para formar professores. Cadernos de Pesquisa, São Paulo, v. 37, n. 130 , jan./abr. 2007, p. 15-41.

MARTINS, Lucia de Araújo Ramos. A visão de licenciandos sobre a formação inicial com vistas à atuação com a diversidade dos alunos. In: CAIADO, Katia Regina Moreno; JESUS, Denise Meyrelles de; BAPTISTA, Claudio Roberto (Org.). Professores e educação especial. Porto Alegre: Mediação, 2011. p. 51-63.

MONTEIRO, Maria Iolanda. Práticas alfabetizadoras: contradições produzindo sucesso e fracasso escolar. AraraquaraSP: JM Editora, 2002.

OLIVEIRA, Luciane Paiva Alves. Práticas para o controle do corpo no início do ensino fundamental: entre a disciplinarização e a não disciplinarização. Dissertação (Mestrado em Educação) - Pontifícia Universidade Católica de São Paulo, 2001.

PEIXOTO, Joana. Tecnologias e práticas: as TIC como instrumentos de mediação. In: LIBÂNEO, José Carlos; SUANNO, Marilza Vanessa Rosa (Org.). Didática e escola em uma sociedade complexa. Goiânia: CEPED, 2011. p. 97-111.

SIMÃO, Ana Lúcia. Escola fundamental de nove anos: em destaque o trabalho do professor do $1^{\circ}$ ano na rede municipal paulistana. Dissertação (Mestrado em Educação: História, Política, Sociedade) - Pontifícia Universidade Católica de São Paulo, 2011.

SOARES, Maria Aparecida Leite. Os processos de inclusão e exclusão das crianças e jovens surdos como estratégia de observação do trabalho escolar. In: FREITAS, Marcos Cezar (Org.). Desigualdade social e diversidade cultural na infância e na juventude. São Paulo: Cortez, 2006. p. 87-109.

TOSCHI, Mirza Seabra. CMDI - comunicação mediada por dispositivo indutor: elemento novo nos processos educativos. In: LIBÂNEO, José Carlos; SUANNO, Marilza Vanessa Rosa (Org.). Didática e escola em uma sociedade complexa. Goiânia: CEPED, 2011. p. 113-131.

VINCENT, Guy; LAHIRE, Bernard; THIN, Daniel. Sobre a teoria e a forma escolar. Educação em Revista, Belo Horizonte, n. 33, jun. 2001, p. 7-47.

WALLON, Henry. Psicologia da educação e da criança. Lisboa: Estampa, 1979.

Artigo recebido em setembro 2013

Aprovado em dezembro 2013. 